\begin{tabular}{l|c|}
\hline & International Journal of Current Research in \\
Biosciences and Plant Biology \\
\hline EXCELLENT \\
PUBLISHERS
\end{tabular}

Original Research Article

doi: $\underline{\text { https://doi.org/10.20546/ijcrbp.2022.901.003 }}$

\title{
Antibacterial potential of some Cameroonian ornamental plants and their isolated endophytic fungi
}

\author{
Lacmata Tamekou Stephen $\mathbb{D}^{\mathbb{D}}$, Tchoupe Tchassem Guy-Bertrand, Ousenu Karimo \\ Kuiate Jules-Roger ${ }^{(D)} *$
}

Research Unit of Microbiology and Antimicrobial Substances, Department of Biochemistry,

Faculty of Science, University of Dschang, Dschang, Cameroon

*Corresponding author; e-mail: jrkuiate@yahoo.com

\begin{abstract}
Article Info
Abstract

Keywords:

Bacterial resistance to antibiotics is a real challenge for health practitioners and society in general Antibacterial activity

Endophytic extract today, bringing a constant need for the search for new molecules. The present study is focused on the antibacterial effect of extracts of three ornamental plants and their endophytes. The endophytic fungi Endophytic fungi

Host plant extracts Ornamental plants isolated from the ornamental plants included Sansevieria trifasciata leaves, Monstera deliciosa fruits, Monstera deliciosa and Cordyline fruticosa roots. The morphocultural features were studied, the antibacterial activities of the endophytes as well as those of their host plant extracts were determined through the agar diffusion and broth microdilution methods. The plant extracts were obtained by ethanol maceration, while those from the endophytes were obtained by ethyl acetate depletion. Phytochemical screening of the different extracts was done using standard methods. Four endophytes were isolated from the three plants: Geotrichum sp. from the leaves of Sansevieria trifasciata; Colletotrichum sp. and Rhizopus sp. from the roots of Cordyline fruticosa and Monstera deliciosa respectively and Phoma sp. from the fruits of Monstera deliciosa. Endophyte isolates inhibited the growth of almost all the tested bacterial with inhibition diameters ranging from 5 to $40 \mathrm{~mm}$. The host endophytic plant extracts were less active than endophytic extracts, with inhibition diameters ranging from 0 to $20 \mathrm{~mm}$. Some endophytic fungal secretions and plant extracts exhibited antibacterial activities in liquid media, with MICs ranging from 512 to $2048 \mu \mathrm{g} / \mathrm{ml}$. Finally, endophytic extracts were more active than plant extracts. There was no concordance between the activities of endophytes and those of plant extracts, reflecting their independence.
\end{abstract}

- Received: 29 October 2021 • Revised: 27 December 2021 • Accepted: 2 January 2022 • Published Online: 6 January 2022

\section{Introduction}

Bacterial resistance to antibiotics has led to therapeutic failures and reduced the range of effective antibiotics available which has directed researchers to find alternative natural sources of new and more effective drugs that would possess low toxicity (Muzzamal et al., 2012). Numerous studies on medicinal plants have 
shown that various classes of metabolites have varying degrees of antibacterial properties (Lacmata et al., 2012; Tamokou et al., 2017) but only a few studies have focused on ornamental plants. However, some microorganisms are powerful producers of antimicrobial substances (Sharma and Shikha Roy, 2015). Among them, endophytes and most particularly those of fungal nature, are increasingly studied (Muzzamal et al., 2012). Since the discovery of the taxol-producing endophytic fungus, Taxomyces andreanae, from the New Pacific (Taxus brevifolia), studies on the isolation and evaluation of endophyte activity from medicinal plants are increasing (Jalgaonwala et al., 2011). They are microbial groups that asymptomatically colonize the interior of plant tissues and play a protective role against plant diseases and infections through their ability to produce antibacterial and antifungal agents besides a variety of extracellular enzymes (Gouda et al., 2016). Thus, knowledge of the interaction that exists between the host plant and endophytes is proving interesting. Efforts on the isolation of endophytes and the study of their natural products are nowadays undertaken. The choice of ornamental plants for this work follows the observation that they tend to be resistant and therefore likely to possess endophytes that would ensure their protection. A question was raised whether the antimicrobial properties of endophytes and plant extracts could justify the resistance of these ornamental plants to pathogen attack and thus provide a new source of antibiotic molecules. The selected plants may harbor endophytic fungi that can be isolated and characterized; the endophytes cultivated on agar medium are thought to have the capacity to produce substances that diffuse in the medium inhibiting bacterial growth. Thus, to valorize the antibacterial potential of endophytic microorganisms, we proposed in the present work to look for endophytic fungi with antimicrobial properties against gram-negative bacteria in ornamental plants. For this purpose, the antibacterial activity of three ornamental plants and colonizing fungal endophytes against Gram-negative bacteria were evaluated after purification and morphocultural characterization of these endophytes.

\section{Materials and methods}

\section{Plant material}

The ornamental plants used in this work were identified at the Cameroon National Herbarium $(\mathrm{CNH})$ in Yaounde. They were: the roots of Cordyline fruticosa
(Hawaiian Spinach) C: /HNC: / not referenced, fruits and roots of Monstera deliciosa (False Philodendron) C: Meise botanical garden HNC: BR0000019806990, leaves of Sansevieria trifasciata Prain (Mother-in-law's Tongue or Knife) C: Dang. D 195 HNC: /not referenced.

\section{Pathogenic bacteria used in the study}

The pathogenic microorganisms used in this work consisted of a reference strain Salmonella typhi ATCC1620, and sixteen Gram-negative bacteria isolated from clinical samples and identified at the Bacteriology and Parasitology Laboratory of the Dschang District Hospital. These clinical isolates included Providencia rettgeri, Klebsiella oxytoca, Citrobacter diversus, Shigella spp., Serratia odorifera, Proteus vulgaris, Pseudomonas aeruginosa 1, Pseudomonas aeruginosa 2, Salmonella paratyphi A2, Salmonella typhi 6 and Escherichia coli.

\section{Isolation and identification of endophytic fungi}

\section{Isolation of endophytic fungi}

The ornamental plants used in this work were collected from a private individual home in Foto at the geographical coordinate's $5^{\circ} 27^{\prime} 51.1^{\prime \prime} \mathrm{N} .10^{\circ} 05^{\prime} 11.9^{\prime \prime}$ E. $5^{\circ} 464195,10086650$ in the Dschang town, in Menoua division of the West region of Cameroon, in November 2019. These collections were made at daybreak at 7:00 am. The different parts of the plants (leaves, roots and fruits) collected were individually wrapped in plastic bags and brought to the laboratory for the study. Part of the plant material was then washed, rinsed with tap water and used for metabolite extraction. The other part after being washed, rinsed then cut with a scalpel to obtain fragments of about $4 \mathrm{~mm}^{2}$ in area, was used for the isolation of endophytic fungi.

The isolation of endophytic fungi was done following the protocol described by Helander et al. (1994) with some slight modifications. The fragments obtained were washed with sterile distilled water, treated with ethanol (70\%) for $2 \mathrm{~min}$ followed by rinsing with sterile distilled water. These samples were then treated with $5 \%$ bleach $(\mathrm{NaOCl})$ for $3 \mathrm{~min}$, and finally rinsed with sterile distilled water. A second treatment with ethanol (70\%) for $30 \mathrm{~s}$ followed by a final rinse with sterile distilled water was performed. Sterilized fragments of plant material (10 fragments per Petri dish $90 \mathrm{~mm}$ ) were 
cultured on PDA medium supplemented with chloramphenicol $(0.5 \mu \mathrm{g} / \mathrm{ml})$ to inhibit the bacterial endophytes' growth. After seeding, the cultures were incubated at $25^{\circ} \mathrm{C}$ for 6 days. Observations were made daily to look for the appearance of mycelial growth. The resulting fungal strains from each fragment were then purified and cultured in Petri dishes containing PDA. All these microbiological manipulations were performed in triplicate and the experiments were repeated three times under aseptic conditions.

\section{Identification and morphocultural characterization of isolated endophytic fungi}

The identification of endophytic fungi was done based on their cultural characteristics and the morphology of fruiting bodies and spores; for this purpose, identification keys were used (Pitt and Hocking, 1985; Botton et al., 1990; Champion, 1997). Fungal strains obtained from each fragment were then purified by center pitting in Petri dishes containing PDA using a patina loop. Pigmentation and appearance were then revealed and identification was made by observation under a light microscope at $1000 \mathrm{X}$ magnification. After purification, an agar disc containing each endophytic fungus was removed and placed in the center of each Petri dish containing the PDA. The radial growth kinetics of the endophytic fungi was revealed by measuring the growth diameters at $48 \mathrm{~h}$ intervals. All these microbiological manipulations were performed in triplicate and the experiments were repeated three times under aseptic conditions.

Evaluation of antibacterial activities of endophytic fungi and plant extracts by the agar diffusion method

\section{Evaluation of the antibacterial activity of endophytic fungi by the agar diffusion method}

Fungal strains purified on PDA medium were deposited on the surface of MHA agar previously spread with an $18 \mathrm{~h}$ bacterial suspension concentrated with 0.5 McFarland. Ciprofloxacin was used as a positive control. The diameters of the growth inhibition zones of the bacterial strain were measured after $24 \mathrm{~h}$ of incubation.

Evaluation of the antibacterial activity of plant extracts by agar diffusion method

A portion of the collected plants was rinsed under tap water for about $10 \mathrm{~min}$ to remove impurities and debris from the surface, then immersed in $70 \%$ ethanol for 1 min, followed by sodium hypochlorite $(\mathrm{NaOCl})(3 \%)$ for $4 \mathrm{~min}$ and ground with mortar and pestle. The resulting grind was macerated with ethanol $(1: 3 \mathrm{w} / \mathrm{v})$ at room temperature for $48 \mathrm{~h}$. Then the extract was filtered through Whatman No. 1 paper and the obtained filtrate was evaporated in a rotary evaporator (BÜCHI R - 200) at $70{ }^{\circ} \mathrm{C}$ and freeze-dried. The extractive yield $(\mathrm{Rd})$ of each plant extract was calculated relative to the mass of fresh material according to the following formula:

$$
\operatorname{Rd}(\%)=\frac{\text { Mass of the obtained extract }(\mathrm{g})}{\text { Mass of the non plant material }(\mathrm{g})} \times 100
$$

Ten $\mu \mathrm{g}$ discs of plant extracts and ciprofloxacin were initially prepared by introducing $10 \mu \mathrm{l}$ of each plant extract prepared at concentrations of $1 \mathrm{mg} / \mathrm{ml}$ and then oven-dried at $40{ }^{\circ} \mathrm{C}$. Using forceps, the discs preimpregnated with extracts and ciprofloxacin discs were deposited on the surface of MHA agar previously spread with a bacterial suspension concentrated to point 0.5 of the McFarland turbidity scale and prepared as described above. The diameters of the bacterial growth inhibition zones were measured after $24 \mathrm{~h}$ of culture. This manipulation was done in triplicate and the experiment was performed three times.

\section{Evaluation of antibacterial activities of endophytic fungi and plant extracts by the microdilution method}

\section{Fermentation and ethyl acetate extraction of endophytic fungi}

Fermentation and extraction were performed following the protocol described by Barik et al. (2010) with some slight modifications. Indeed, endophytic fungi that tested positive for identification and screening for antimicrobial activity were grown on PDA at $25^{\circ} \mathrm{C}$ for six days, two pieces $(0.5 \times 0.5 \mathrm{~cm})$ of each fungus were inoculated into $500 \mathrm{ml}$ Erlenmeyer flasks containing $300 \mathrm{ml}$ PDB (Potato Dextrose Broth) and this was repeated twice, they were then incubated at $25{ }^{\circ} \mathrm{C}$ for one week with regular shaking at $150 \mathrm{rpm}$; after incubation, the contents were filtered through the sterile gaze to separate the mycelium from the broth culture. The latter was centrifuged at $3000 \mathrm{rpm}$ for $10 \mathrm{~min}$, and the supernatant recovered. Extraction was performed with ethyl acetate; to each filtrate, an equal volume of solvent was added and shook for two hours, the resulting solution was then allowed to stand in 
separating funnels to separate the two phases, and the organic phase was concentrated under pressure using a rotary evaporator at $45{ }^{\circ} \mathrm{C}$. The extractive yield (Rd) of each plant endophyte fungus extract was calculated relative to the endophyte fungus culture media volume using the following formula:

$$
\operatorname{Rd}(\%)=\frac{\text { Mass of the extract }(\mathrm{g})}{\text { volume of the midium }(\mathrm{l})} \times 100
$$

\section{Determination of Minimum Inhibitory Concentrations (MIC) and Minimum Bactericidal Concentrations (MBC) of endophytic fungi and plant extracts}

The inhibitory potential of bacterial growth of plant extracts and fungal endophytes was determined by the microdilution method as described by Mativandlela et al. (2006) with some modifications. In each well of a 96-well microplate, $100 \mu \mathrm{l}$ of culture broth (MHB) was introduced, then $100 \mu \mathrm{l}$ of each extract was introduced into the first 3 wells of the first row, respectively; thereafter serial dilutions following a geometric progression of reason 2 were performed. A volume of $100 \mu \mathrm{l}$ of culture broth and the bacterial inoculum was introduced into each well. Plates were brought to incubation while agitating at $37{ }^{\circ} \mathrm{C}$ for $18 \mathrm{~h}$. Wells containing the inoculum as well as those containing only the culture media and DMSO were made to constitute the negative and neutral controls, respectively. After this incubation time, the revelation was done using a $0.2 \%$ aqueous paraiodonitrotetrazolium chloride (INT) bromide solution (Mativandlela et al., 2006). All concentrations that prevented the appearance of pink color were taken as the inhibitory concentrations and the lowest was scored as MIC. For each extract, three columns were made and the revelation was done on two columns. The third column was used to determine the Minimum Bactericidal Concentrations. This test was performed three times.

After reading the different MICs, $150 \mu \mathrm{l}$ of MHB were introduced into the wells of the new plate, and then 50 $\mu l$ of the content of each well where there was an inhibition of bacterial growth were taken with a micropipette and introduced into the corresponding wells of the new plate. These plates were then covered with a sterile lid. Neutral and negative control wells, containing $\mathrm{MHB}$ and those containing the inoculum without extract and antibiotics respectively were made. The microplates were incubated again under agitation at $37{ }^{\circ} \mathrm{C}$ for $48 \mathrm{~h}$ and then revealed with INT as earlier mentioned. All extract concentrations for which the absence of bacterial growth was noted, were considered as bactericidal concentrations and the smallest was noted as MBC. This test was repeated 3 times.

\section{Phytochemical screening}

Bioactive substances of endophytes and different plant extracts were screened according to standard methods as described by Harbone (1973).

\section{Statistical analysis}

The data obtained were expressed as mean \pm standard deviation and were subjected to analysis of variance (ANOVA). The differences between the means when they existed were evaluated using the Waller-Duncan test at the 5\% probability threshold; SPSS version 22.0 for Windows was used for statistical analysis. Microsoft Word and Excel were used for data entry and processing.

\section{Results}

\section{Extractive yield and physical characteristics of the extracts}

Table 1 presents the extraction yields of the plants, the colors, as well as the physical aspects of the extracts obtained. From this table, it appears that the extract of the fruits of $M$. deliciosa has the highest extraction yield $(13.4 \%)$, while the roots of the plant showed a yield of $6.2 \%$, followed by the extract of Sansevieria trifasciata whose yield is $8.4 \%$ and $6.4 \%$ for the extract of the root of Cordyline fruticosa. In addition, the colors and physical aspects variation from one extract to another was noted.

The extraction yields of the endophytic fungi, the colors, as well as the obtained physical aspects, are presented in Table 2. From this table, it appears that the endophytic's extract from the fruits of $M$. deliciosa had the highest extraction yield $(10 \%)$, while those of the roots of the plant presented a yield of $9.33 \%$ followed by that of S. trifasciata whose yield was $8.33 \%$; and $5.66 \%$ for the one of the root of C. fruticosa. In addition, we noted that the colors and physical aspects vary from one extract to another. 
Table 1. Extraction yields and physical characteristics of plant extracts.

\begin{tabular}{lllll}
\hline Host plants & Used parts & Yield (\%) & Aspects & Colors \\
\hline Sansevieria trifasciata & Leaves & 8.4 & Smooth & Greenish \\
Cordyline fruticosa & Roots & 6.4 & Liquid & Blackish \\
Monstera deliciosa & Fruits & 13.4 & Liquid & Black \\
& Roots & 6.2 & Smooth & Brown \\
\hline
\end{tabular}

Table 2. Extraction yields and physical characteristics of endophytic fungi extracts.

\begin{tabular}{llll}
\hline Host plants & Used parts & Yield (g/l) & Aspects \\
\hline Sansevieria trifasciata & Leaves & 08.33 & Colors \\
Cordyline fruticosa & Roots & 05.66 & Liquid \\
Monstera deliciosa & Fruits & 10.00 & Liquid \\
& Roots & 09.33 & Smooth \\
\hline
\end{tabular}

\section{Isolated endophytes and their morphocultural characteristics}

The different endophytic fungi isolated from the different plants and the number of times they were isolated are presented in Table 3 below. From this table, it was found that for each plant part only one endophyte was isolated on three occasions. Figs. 1, 2, 3 and 4 below show respectively the morphocultural characteristics (the general aspect of the colonies pigmentation of the endophytic fungi and microscopic characteristics) of the isolated endophytic fungi.

Table 3. Endophytic fungi isolated from different parts of plants.

\begin{tabular}{lcl}
\hline Host plants (parts used) & Endophytes codes & Number of isolation times \\
\hline S. trifasciata (Leaves) & 3F1 & 03 \\
C. fruticosa (Roots) & 5R1 & 03 \\
M. deliciosa (Fruits) & 4FR1 & 03 \\
M. deliciosa (Roots) & 4R4 & 03 \\
\hline
\end{tabular}

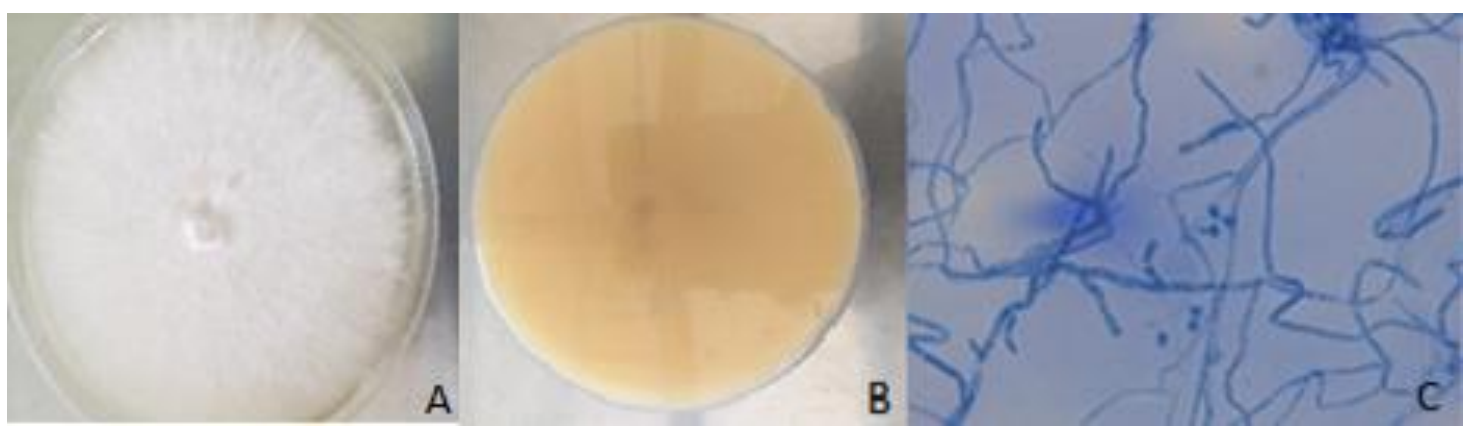

Fig. 1: Endophytic fungus isolated from Sansevieria trifasciata leaves (A: front view; B: back view; C: conidia and filaments seen under 1000X microscope).

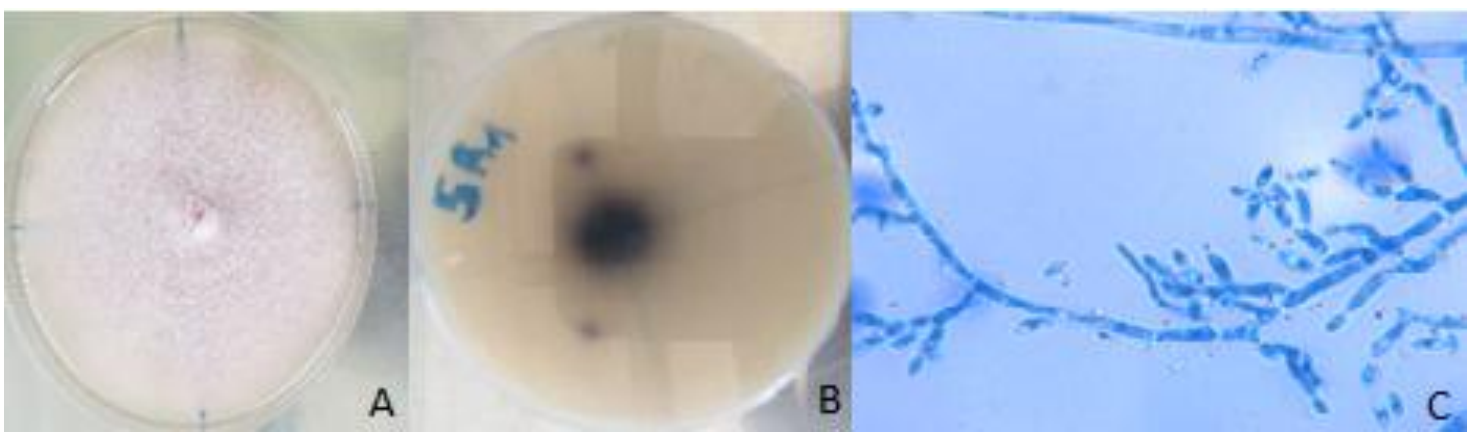

Fig. 2: Endophytic fungus isolated from Cordyline fruticosa roots (A: front view; B: back view; C: conidia and filaments seen under $1000 \mathrm{X}$ microscope). 
It appears that endophytes isolated from $S$. trifasciata present a macroscopic whitish cottony and fluffy aspect on the front, an orange pigmentation on the back and microscopically it presents microconidia and mycelial filaments belonging to Geotrichum spp. From Fig. 3, it appears that the endophytic fungus isolated from the leaves of Cordyline fruticosa roots presents a macroscopic cottony and pinkish downy aspect on the front side, an orange pigmentation on the backside. Microscopic observation shows microconidia and mycelial filaments belonging to Colletotrichum spp.

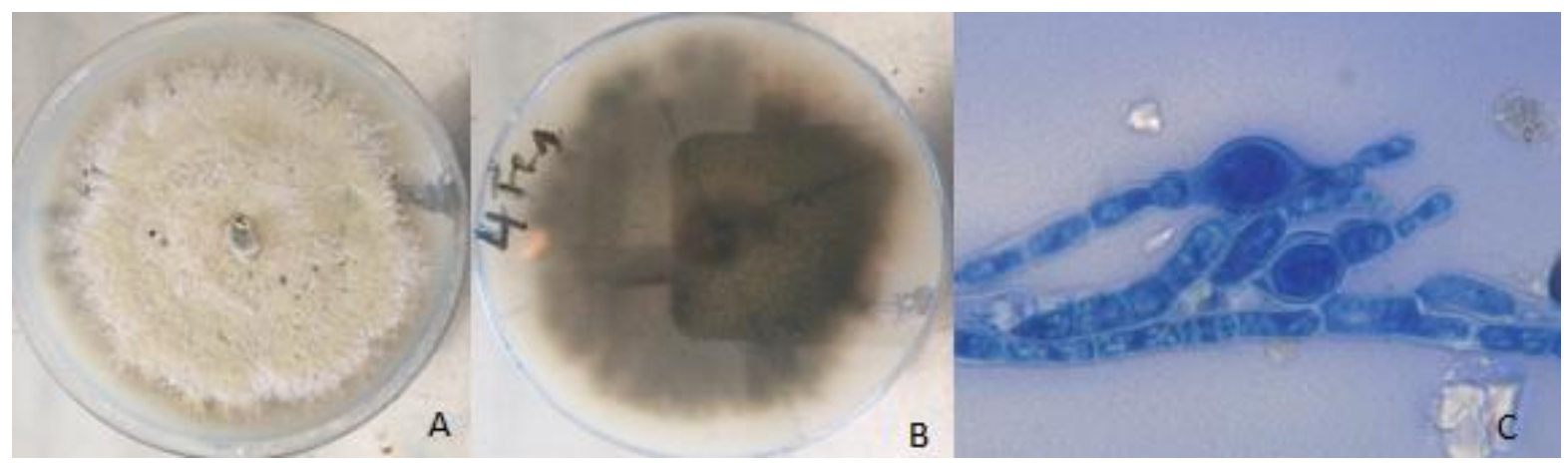

Fig. 3: Morphocultural characteristics of the endophytic fungus isolated from the fruits of Monstera deliciosa (A: front view; B: back view; C: conidia and filaments seen under a 1000X microscope).

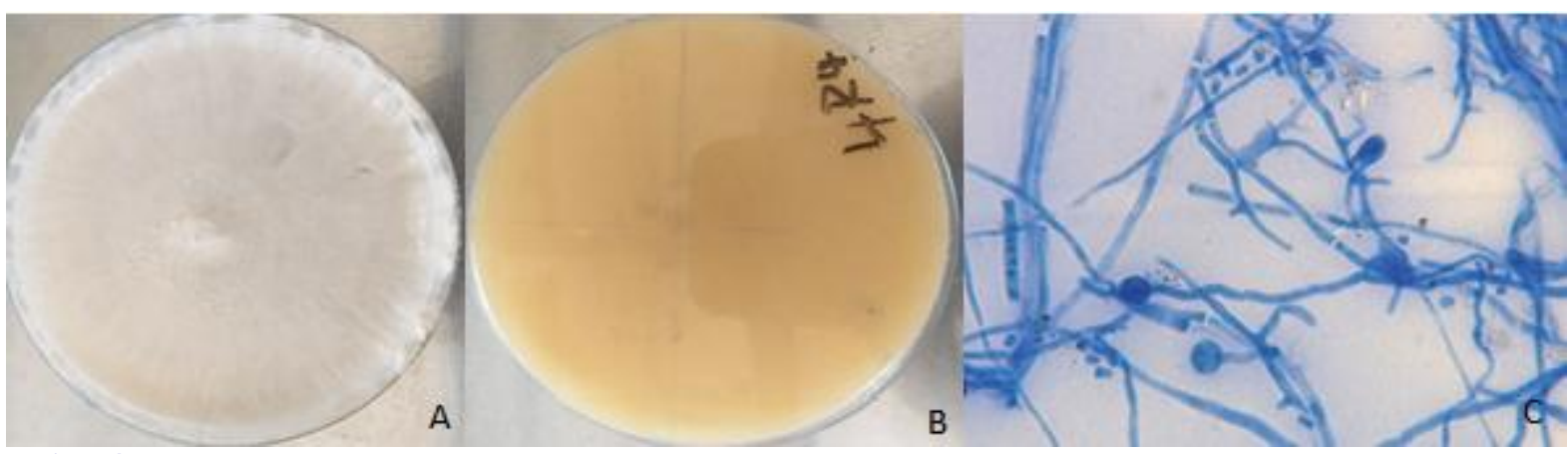

Fig. 4: Morphocultural characteristics of the endophytic fungus isolated from the roots of Monstera deliciosa (A: front view; B: back view; C: conidia and filaments seen under 1000X microscope).

From Fig. 4, it can be observed on the front side of the plates, a greenish-white downy and powdery macroscopic aspect; whereas, on the backside of the plates, a dark brown pigmentation was observed. The microscopic observation shows mycelial filaments and chlamydospores of Phoma spp.

It is evident from Fig. 4 that the endophytic fungus isolated from the roots of $M$. deliciosa has a macroscopic whitish cottony appearance on the front side, with light orange pigmentation on the reverse side of the plate. Microscopic observation shows mycelial filaments, microconidia and chlamydospores belonging to Rhizopus spp.

\section{Radial growth kinetics}

Fig. 5 shows the graphical comparison of radial growth kinetics of mycoendophytes isolated from different extracts of ornamental plants. The evolution of radial growth diameters was monitored for eight days. The plant endophytic fungi tested by the agar diffusion method have gradually increased growth diameters between the first and the last incubation day. The endophytic fungi isolated from the fruits of $M$. deliciosa showed a faster radial growth than others, followed by the endophytic fungi from $S$. trifasciata leaf extract, while the roots of $M$. deliciosa showed almost the same radial growth; on the other hand, those from the roots of C. fruticosa showed the lowest radial growth. 


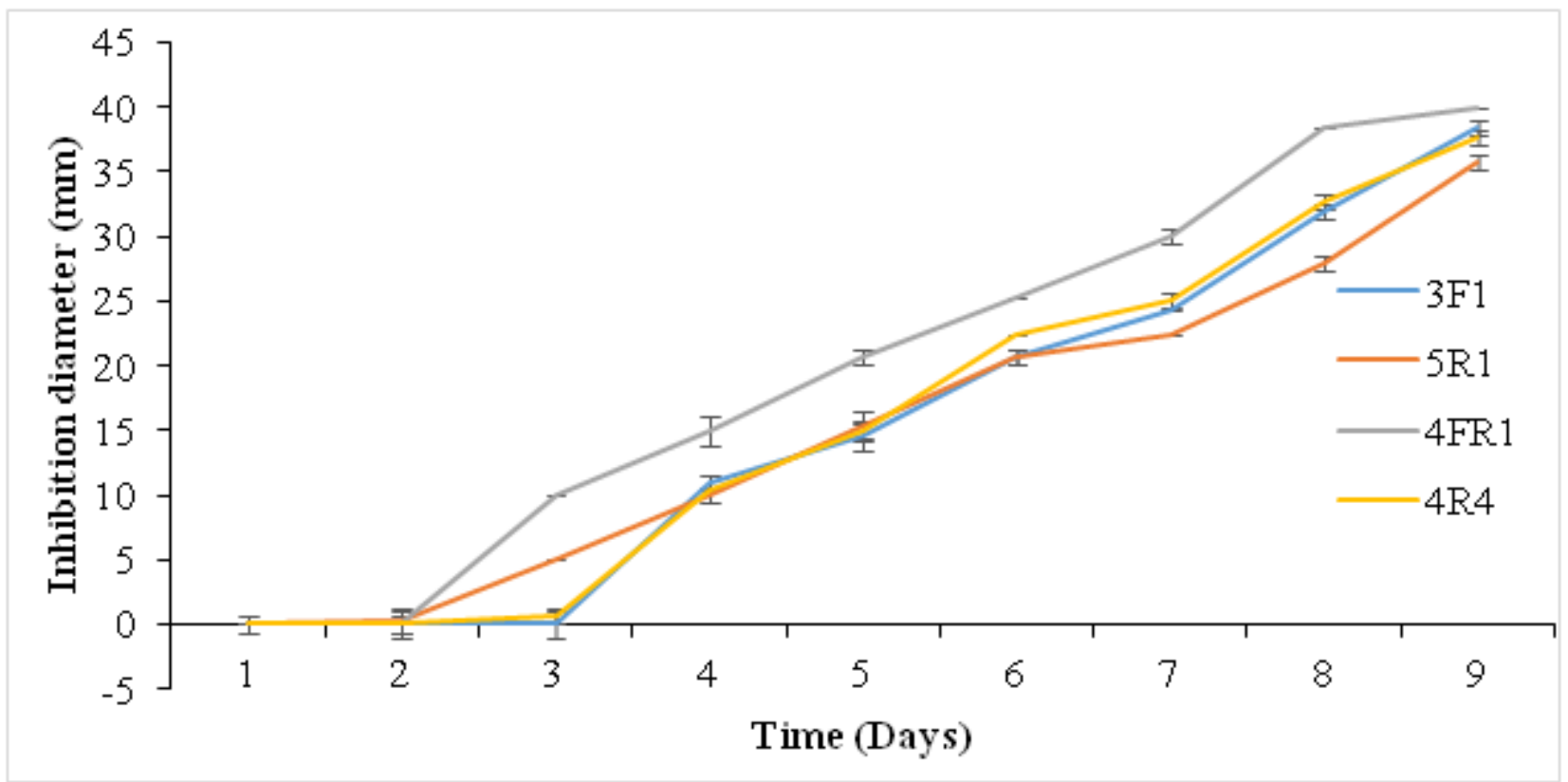

Fig. 5: Comparison of the radial growth diameters of the different endophytic fungi (3F1, 5R1, 4FR1 and 4R4).

\section{Antibacterial activities of endophytic fungi and crude plant extracts}

The antibacterial activity of endophytic fungi and crude extracts from ornamental plants was determined by agar diffusion and microdilution techniques against 16
Gram-negative bacterial isolates and one reference strain. Antibacterial activities of endophytic fungi and crude plant extracts were tested by the agar diffusion technique. Table 4 summarizes the diameter of inhibition of bacterial growth by endophytic fungi and raw plant extracts.

Table 4: Growth inhibition diameter of pathogenic bacteria by extract host plant assessed ( $\mathrm{mm}$ ) by agar diffusion technique.

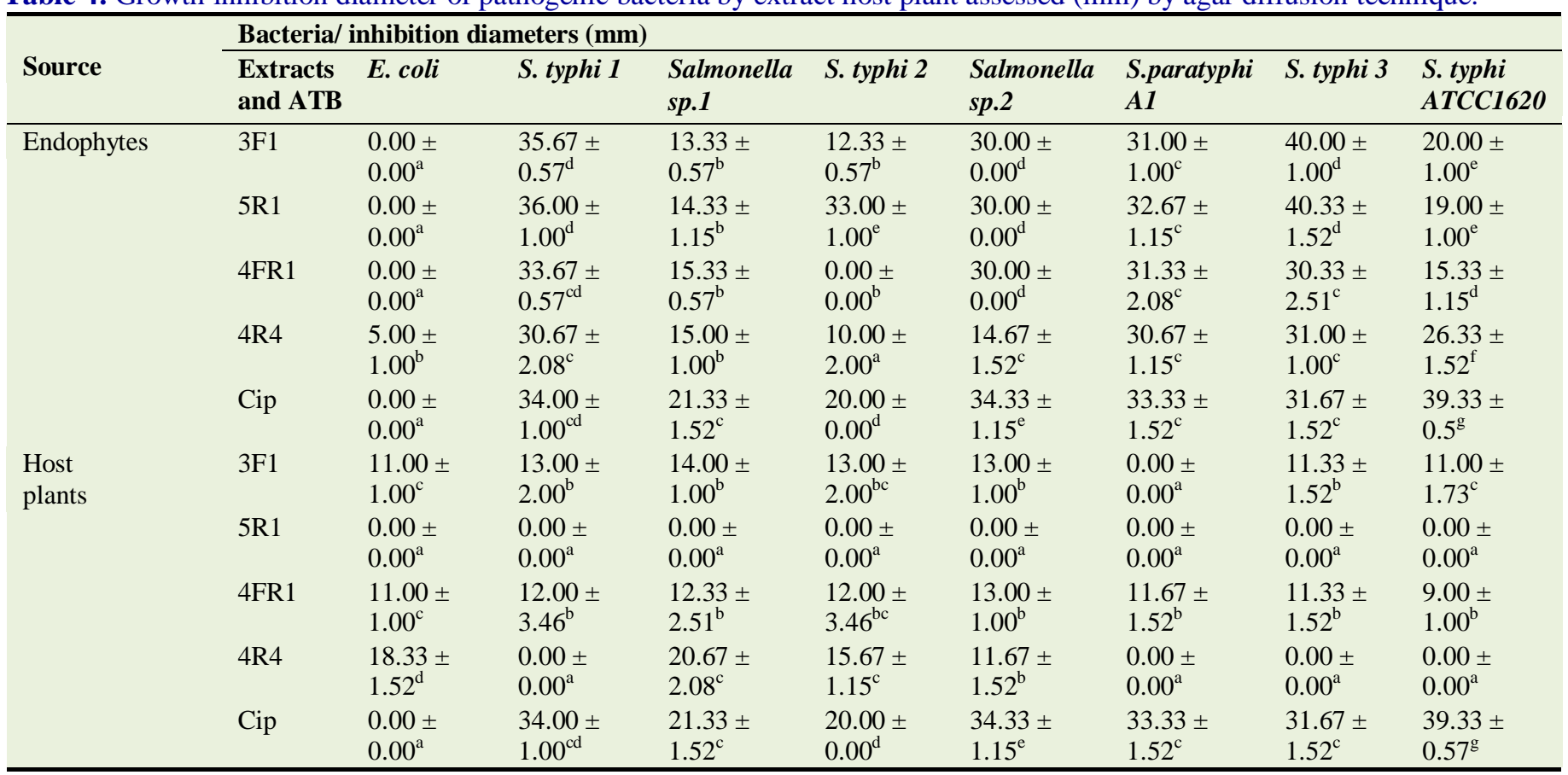


Table 4: Continued..

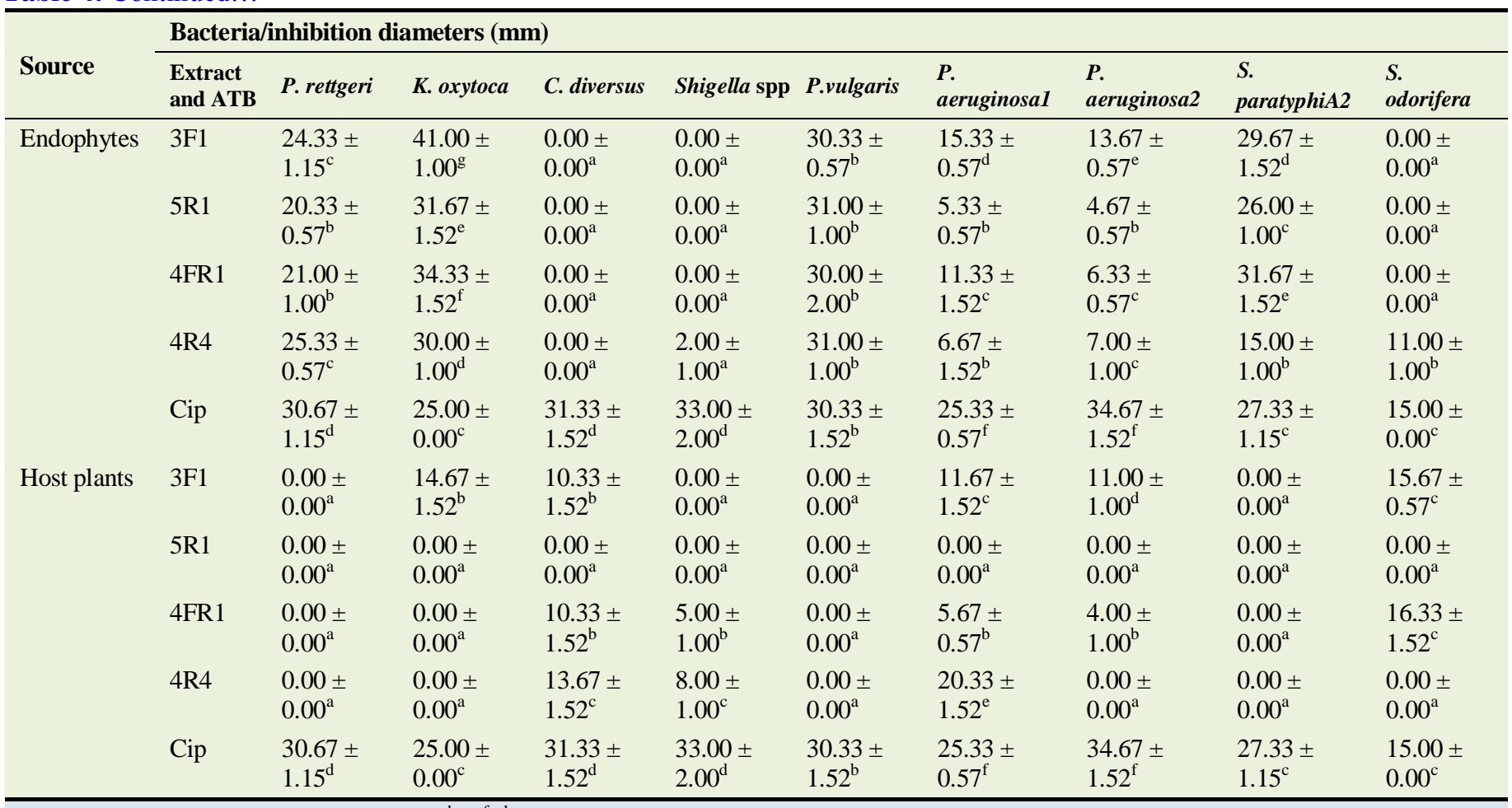

Cip: ciprofloxacin (reference antibiotic); ${ }^{\text {a,b,c,e,f,g,h }}:$ diameter means assigned the same letter in the same column (same strain) are not significantly different. Waller Duncan multiple tests at $\mathrm{P} \leq 0.05$.

Table 4 shows that the endophytic fungi tested by the agar diffusion method have varied antibacterial activities, with inhibition diameters generally ranging from 1 to $40 \mathrm{~mm}$. The $C$. fruticosa root extract showed the highest spectrum of activity (active on $78.94 \%$ of the tested bacteria), followed by $M$. deliciosa fruit extract, $M$. deliciosa root extract and S. trifasciata leaf extract (active on $57.89 \%$ of the tested bacteria). On the other hand, Table 5 shows that the tested plant extracts by the agar diffusion method have varied antibacterial activities, with inhibition diameters generally ranging from 1 to $20 \mathrm{~mm}$.

The fruit extract of $M$. deliciosa showed the highest spectrum of activity (active on $61.11 \%$ of the tested bacteria) followed by the root extract of $M$. deliciosa and the leaf extract of S. trifasciata (active on $50 \%$ of the bacteria tested), and finally the root extract of $C$. fruticosa which showed no activity. The analysis of this table shows us that in general, the endophytic fungi isolated respectively from the tested plant parts were more active with diameters of inhibition much higher than those of the plant parts.

\section{Antibacterial activities of endophytic fungi and crude plant extract by microdilution technique}

The results of antibacterial activity of the endophytic fungi and plant extracts as determined by evaluating the MIC and MBC of each sample against 16 Gram-negative bacterial isolates and a reference strain are shown in Tables 5 and 6 . The plant extracts tested by microdilution methods have varied antibacterial activities with MICs generally ranging from 1024 to $2048 \mu \mathrm{g} / \mathrm{ml}$ (Table 5). The fruit extract of $M$. deliciosa showed the highest spectrum of activity (active on $44.44 \%$ of bacteria), followed by the root extracts of $M$. deliciosa (active on $33.33 \%$ of bacteria) and finally the leaves extract of $S$. trifasciata. The extracts of roots of $C$. fruticosa did not present any antibacterial activity. Table 6 shows that the extracts of endophytic fungi tested by the microdilution method have varied antibacterial activities, with MICs generally ranging from 512 to $1024 \mu \mathrm{g} / \mathrm{ml}$. On the one hand, the ethyl acetate extract of $S$. trifasciata leaves was the most active, that is on $29.41 \%$ of bacteria followed by the ethyl acetate extract of $M$. deliciosa and C. fruticosa roots with a growth inhibition of $23.52 \%$ of bacteria. 
Table 5. Antibacterial activity (MIC, MBC and MIC/MBC ratio) of crude extracts ( $\mu \mathrm{g} / \mathrm{ml}$ ).

\begin{tabular}{|c|c|c|c|c|c|c|c|c|c|c|c|c|c|c|c|}
\hline \multirow[t]{2}{*}{ Bacterial strains } & \multicolumn{3}{|c|}{$\begin{array}{l}\text { M. deliciosa } \\
\text { (Fruits) }\end{array}$} & \multicolumn{3}{|c|}{$\begin{array}{l}\text { S. trifasciata } \\
\text { (Leaves) }\end{array}$} & \multicolumn{3}{|c|}{$\begin{array}{l}\text { C. fruticosa } \\
\text { (Roots) }\end{array}$} & \multicolumn{2}{|c|}{$\begin{array}{l}\text { M. deliciosa } \\
\text { (Roots) }\end{array}$} & \multicolumn{4}{|c|}{ Ciprofloxacine } \\
\hline & MIC & MBC & $\mathbf{R}$ & MIC & MBC & $\mathbf{R}$ & MIC & MBC & $\mathbf{R}$ & MIC & MBC & $\mathbf{R}$ & MIC & MBC & $\mathbf{R}$ \\
\hline S. paratyphi Al & 2048 & 2048 & 1 & 2048 & - & $n d$ & - & - & nd & 2048 & - & nd & $<0.25$ & $<0.25$ & nd \\
\hline S. paratyphi A2 & 1024 & 2048 & 2 & 1024 & 2048 & 2 & - & - & nd & 2048 & - & nd & $<0.25$ & $<0.25$ & nd \\
\hline K. oxytoca & 2048 & - & nd & - & - & nd & - & - & nd & - & - & nd & $<0.25$ & $<0.25$ & nd \\
\hline S. typhi 1 & - & - & nd & - & - & nd & - & - & nd & - & - & nd & $<0.25$ & $<0.25$ & nd \\
\hline S. odorifera & 2048 & - & nd & - & - & nd & - & - & nd & 2048 & - & nd & - & - & nd \\
\hline S. typhi ATCC1620 & - & - & nd & - & - & nd & - & - & nd & - & - & nd & $<0.25$ & 0.5 & nd \\
\hline S. typhi 2 & - & - & nd & - & - & nd & - & - & nd & - & - & nd & $<0.25$ & $<0.25$ & nd \\
\hline P. vulgaris & - & - & nd & - & - & nd & - & - & nd & 1024 & 2048 & 2 & $<0.25$ & 0.5 & nd \\
\hline Salmonella sp. 1 & - & - & nd & - & - & nd & - & - & nd & - & - & nd & - & - & nd \\
\hline Salmonella sp. 2 & - & - & nd & - & - & nd & - & - & nd & 2048 & - & nd & $<0.25$ & 0.5 & nd \\
\hline Shigella sp. & - & - & nd & - & - & nd & - & - & nd & - & - & nd & 32 & $>32$ & nd \\
\hline P. rettgeri & 2048 & 2048 & 1 & 2048 & - & nd & - & - & nd & - & - & nd & 0.5 & 0.5 & 1 \\
\hline S. typhi 3 & - & - & nd & 2048 & - & nd & - & - & nd & - & - & nd & $<0.25$ & $<0.25$ & nd \\
\hline E. coli & 2048 & - & nd & - & - & nd & - & - & nd & - & - & nd & 32 & $>32$ & nd \\
\hline P. aeruginosa 1 & 2048 & - & nd & - & - & nd & - & - & nd & 2048 & - & nd & $<0.25$ & $<0.25$ & nd \\
\hline P. aeruginosa 2 & 2048 & - & nd & - & - & nd & - & - & nd & - & - & nd & $<0.25$ & $<0.25$ & nd \\
\hline C. diversus & - & - & nd & 2048 & - & 1 & - & - & nd & - & - & nd & $<0.25$ & $<0.25$ & $\mathrm{Nd}$ \\
\hline
\end{tabular}

R: ratio MBC/MIC; - : MIC or MBC $>2048 \mu \mathrm{g} / \mathrm{ml}$ or inactive; MIC: Minimum Inhibitory Concentration; MBC: Minimum Bactericidal Concentration; nd: not determined.

Table 6. Antibacterial activity (MIC, MBC and MIC/MBC ratio) of endophytic fungi extracts: ( $\mu \mathrm{g} / \mathrm{ml})$.

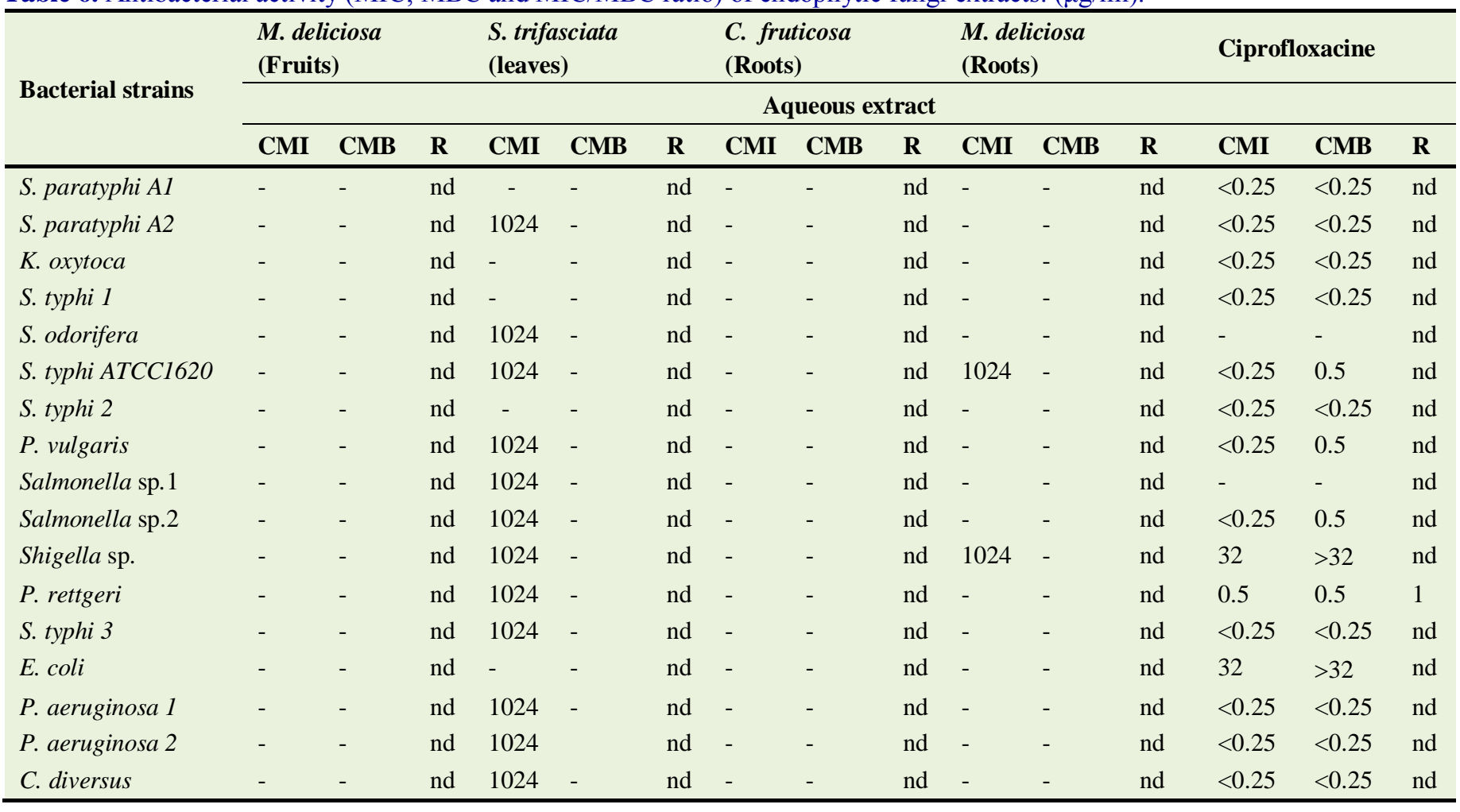


Table 6. Continued...

\begin{tabular}{|c|c|c|c|c|c|c|c|c|c|c|c|c|c|c|c|}
\hline \multirow[b]{2}{*}{ Bacterial strains } & \multicolumn{3}{|c|}{$\begin{array}{l}\text { M. deliciosa } \\
\text { (Fruits) }\end{array}$} & \multicolumn{3}{|c|}{$\begin{array}{l}\text { S. trifasciata } \\
\text { (leaves) }\end{array}$} & \multicolumn{3}{|c|}{$\begin{array}{l}\text { C. fruticosa } \\
\text { (Roots) }\end{array}$} & \multicolumn{2}{|c|}{$\begin{array}{l}\text { M. deliciosa } \\
\text { (Roots) }\end{array}$} & \multicolumn{4}{|c|}{ Ciprofloxacine } \\
\hline & \multicolumn{15}{|c|}{ Aqueous extract } \\
\hline \multicolumn{16}{|c|}{ Endophytic fungi host extract } \\
\hline S. paratyphi Al & - & - & nd & - & - & nd & - & - & nd & - & - & nd & $<0.25$ & $<0.25$ & nd \\
\hline S. typhil & - & - & nd & 1024 & - & nd & - & - & nd & - & - & nd & $<0.25$ & $<0.25$ & nd \\
\hline S. odorifera & - & - & nd & 1024 & - & nd & 1024 & - & nd & 1024 & - & nd & - & - & nd \\
\hline S. typhi ATCC1620 & 1024 & - & nd & - & - & nd & - & - & nd & - & - & nd & $<0.25$ & 0.5 & nd \\
\hline S. typhi2 & - & - & nd & - & - & nd & - & - & nd & 1024 & - & nd & $<0.25$ & $<0.25$ & nd \\
\hline P. rettgeri & - & - & nd & - & - & nd & 1024 & - & nd & - & - & nd & 0.5 & 0.5 & 1 \\
\hline S. typhi3 & - & - & nd & - & - & nd & - & - & nd & - & - & nd & $<0.25$ & $<0.25$ & nd \\
\hline E. coli & - & - & nd & - & - & nd & - & - & nd & - & - & nd & 32 & $>32$ & nd \\
\hline P. aeruginosa 1 & - & - & nd & - & - & nd & - & - & nd & - & - & nd & $<0.25$ & $<0.25$ & nd \\
\hline P. aeruginosa 2 & - & - & nd & - & - & nd & 1024 & - & nd & - & - & nd & $<0.25$ & $<0.25$ & nd \\
\hline C. diversus & - & - & nd & - & - & nd & & - & nd & - & - & nd & $<0.25$ & $<0.25$ & $\mathrm{Nd}$ \\
\hline
\end{tabular}

R: ratio CMB / CMI; - : CMI or CMB >1024 or inactive; CMI: Minimum Inhibitory Concentration; MBC: Minimum Bactericidal Concentration; nd: not determined.

Table 7. Qualitative chemical composition of ethyl acetate extracts (EA) and aqueous residues (AqR) of endophytic fungi and ethanolic extract of the host plant (HP).

\begin{tabular}{|c|c|c|c|c|c|c|c|c|c|c|c|c|}
\hline \multirow{2}{*}{ Secondary metabolite } & \multicolumn{3}{|c|}{ M. deliciosa (Fruits) } & \multicolumn{3}{|c|}{ M. deliciosa (Roots) } & \multicolumn{3}{|c|}{ S. trifasciata (Leaves) } & \multicolumn{3}{|c|}{ C. fruticosa (Roots) } \\
\hline & $\operatorname{AqR}$ & EA & HP & $\mathbf{A q R}$ & EA & HP & AqR & EA & HP & $\mathbf{A q R}$ & EA & HP \\
\hline Alkaloids & + & - & - & + & - & + & - & - & - & + & + & + \\
\hline Flavonoids & - & - & - & - & + & - & - & - & + & + & + & + \\
\hline Anthraquinones & + & + & + & + & + & - & + & + & + & + & - & + \\
\hline Triterpenoids & - & - & + & - & - & + & - & - & + & + & - & + \\
\hline Sterols & - & - & - & - & - & - & - & - & - & - & + & - \\
\hline Saponins & - & - & + & - & - & + & - & - & - & - & + & + \\
\hline
\end{tabular}

(-): Absent; (+): Present; AqR: Aqueous extract; EA: Ethyl Acetate extract; HP: Endophytic Host Plant extract.

The ethyl acetate extract of $M$. deliciosa fruits was active only on $11.76 \%$ of bacteria. On the other hand, the aqueous residue of $S$. trifasciata leaves was more active on $70.58 \%$ of bacteria followed by the aqueous residue of $M$. deliciosa roots active on $11.76 \%$ of bacteria. Tables 5 and 6 analysis showed that the ethyl acetate extracts and aqueous residues of endophytic fungi are more active than the extracts of their corresponding host plant parts.

\section{Phytochemical screening}

Table 7 shows the qualitative chemical composition of the endophytic and host plant extracts used. From this 
table, it appears that except for the aqueous and ethyl acetate residues of $C$. fruticosa root which contain the majority of the secondary metabolite classes highlighted in this work, all other aqueous and ethyl acetate residues of endophytic fungi have selectively distributed secondary metabolites.

\section{Discussion}

For each plant part, the same endophytic fungus was isolated three times in a row. This could reflect the fact that the isolated mycoendophytes are not opportunistic. Ethanolic extracts of ornamental plants and endophytic fungi obtained after isolation and extraction were examined based on their antimicrobial activity by disc diffusion and microdilution methods. These different samples showed varying degrees of antimicrobial activity, with zones of inhibition ranging from 0 to 40 $\mathrm{mm}$ for the isolated endophytic fungi, and 0 to $20 \mathrm{~mm}$ for the ornamental plant extracts. These results corroborate those from Elfita et al. (2019) who revealed that plant extracts, as well as their endophytic fungi, inhibit the growth of several bacterial strains, especially Gram-negative ones.

The phytochemical screening carried out on all the extracts of ornamental plants as well as their endophytic fungi indicated in a general way the presence of several classes of chemical compounds. Each extract presented at least two secondary metabolites classes with antimicrobial properties, the antibacterial activities observed with these extracts would be due to the presence of these bioactive compounds. Several works have already demonstrated the antibacterial properties of secondary metabolites from plant extracts and their endophytic fungi (Cowan, 1999; Basli et al., 2012).

Among the plant extracts, the extracts of $M$. deliciosa fruit, S. trifasciata leaves and M. deliciosa root showed antibacterial activities towards some bacterial strains. According to the phytochemical screening carried out, these extracts contained a wide variety of bioactive secondary metabolites among which are polyphenols and tannins. Scalbert (1991), Rodrigues et al. (2014) have highlighted the important antibacterial activity of polyphenols whose mechanism would be the action on the metabolism of the bacterial cell, especially by inhibition of enzymes of oxidative phosphorylation of the electron transport system, inactivation of adhesins and proteins of the cell envelope which would confer their antibacterial power to the extracts mentioned.
Moreover, the antibacterial activity of these extracts would be also attributed to the presence of the tannins (Djipa et al., 2000). Indeed, the capacity of tannins to act in many sites could explain the broad antibacterial spectrum presented by this extract towards the tested bacterial strains.

Similarly, still in view of the phytochemical screening of the endophytic fungi extracts, we noticed the presence of various metabolites and the presence of polyphenols in all the extracts of fungal endophytes having an inhibiting activity on the growth of some of the pathogens. The fungi isolated from the plants as well as their extracts showed some of them with good antibacterial activities. These results corroborate those found by the investigations of Eze et al. (2019) who showed that several endophytic fungi isolated from ornamental plants were endowed with antibacterial properties.

However, the classification scale of antibacterial activities proposed by Tamokou et al. (2017) permitted us to present the tested extracts according to the bacterial strains significant; moderate, and low activities. Indeed, according to this scale the extract of a plant part is said to be very active if it presents a MIC $<100 \mathrm{~g} / \mathrm{ml}$, significantly active if $100 \leq \mathrm{MIC} \leq 512$ $\mathrm{g} / \mathrm{ml}$, moderately active when $512<$ MIC $\leq 2048 \mathrm{~g} / \mathrm{ml}$ and weakly active for a MIC $>2048 \mathrm{~g} / \mathrm{ml}$. Thus in this work, the extracts of $S$. trifasciata leaves, $M$. deliciosa fruits towards $S$. paratyphi A with MICs of $1024 \mathrm{~g} / \mathrm{ml}$ as well as that of $M$. deliciosa roots towards $P$. vulgaris with MIC of $1024 \mathrm{~g} / \mathrm{ml}$ were found to be moderately active. For the endophytic fungi extracts, the ethyl acetate extracts of $S$. trifasciata leaves and $M$. deliciosa roots towards Salmonella spp. with MICs of $512 \mathrm{~g} / \mathrm{ml}$ as well as the $M$. deliciosa root extract towards $K$. oxytoca with a MIC of $512 \mathrm{~g} / \mathrm{ml}$ were significantly active. The aqueous residue of the leaves of $S$. trifasciata was moderately active on nearly $70 \%$ of the germs tested. These activities would be attributed to the presence in these extracts of classes of secondary metabolites whose antibacterial activity has already been demonstrated; notably tannins, triterpenes, steroids and polyphenols which is in the same direction as the work carried out by Elfita et al. (2019) on the aqueous and ethyl acetate extracts of endophytic fungi from plants of the same families as those studied in this work. The latter revealed that these extracts had very good antibacterial activities against some susceptible and resistant bacterial strains. 
On the other hand, we noted that some extracts of plants and endophytic fungi such as that of the roots of $C$. fruticosa presented very weak activity spectra. These results contradict those of Elfita et al. (2019) who demonstrated that the leaves of $C$. fruticosa would be endowed with antibacterial activities. This could be explained by qualitative and quantitative harvesting factors that would largely influence their biological activities. It could be that according to the period of harvest and the part of the plant used, bioactive compounds are absent or they are present in very weak quantity in these extracts (Harbone et al. 1999). On the other hand, we can think that bacterial resistance mechanisms would have prevented the extracts from accumulating at the intracellular level to exert their deleterious effects (Basli et al., 2012).

In comparison, in disc diffusion and microdilution tests, the endophytic fungal extracts showed a much higher spectrum of activity against a number of pathogenic bacteria than the crude plant extracts. This can be observed through the differences in inhibition diameters and MIC. These results corroborate those of Eze et al. (2019) who showed that secondary metabolites would better be produced in endophytes in favorable seasons than in plants; this justifies also the better activities obtained in endophytic fungi both by agar diffusion and microdilution. From these observations, the production of bioactive substances by the endophytes could be directly associated with that of the host plant. Endophytic fungi isolated from ornamental plants are believed to possess antibacterial powers that to some extent protect the plants from attacks by infectious agents Sushanto et al. (2016). These microorganisms could have incorporated informational genes from higher plants, which would allow them to better adapt to the host plant and perform certain functions such as protection against various types of pathogens, insects and grazing animals (Strobel, 2003). Thus, they would represent a strong line of defense for plants as shown by the work of Eze et al. (2019).

\section{Conclusions}

In the spirit of valorizing the antibacterial potential of endophytic microorganisms, we proposed to look for endophytic fungi with antimicrobial properties against Gram-negative bacteria in ornamental plants. This revealed that: Each of the three plants studied in this work, has at least one endophytic fungus; mycoendophytes presented relatively high inhibition diameters on the majority of bacterial isolates in solid media, which indicates that they produce substances in the medium that inhibit bacterial growth. The same activities were significantly more pronounced than the activities of the host plants; Extracts of endophytic fungi obtained showed lesser activities as well as the plant extracts in broth culture. Finally, the leaves of $S$. trifasciata, the fruits of $M$. deliciosa, the roots of $C$. fruticosa and $M$. deliciosa possess endophytic fungi whose antimicrobial activities are not correlated with those of the plants that host them.

\section{Conflict of interest statement}

Authors declare that they have no conflict of interest.

\section{References}

Barik, B.P., Tayung, K., Jagadev, P.N., Dutta, S.K., 2010. Phylogenetic placement of an endophytic fungus Fusarium oxysporum isolated from Acorus calamus rhizomes with antimicrobial activity. Eur. J. Biol. Sci., 20(11): 8-16.

Basli, A., Chibane, M., Madani, K., Oukil, N., 2012. Activité antibactérienne des polyphénols extraits d'une plante médicinale de la flore d'Algérie: Origanum glandulosum Desf. Phytothérapie, 10: 2-9.

Botton, B., Breton, A., Fevre, M., Guy, P.H., Iarpent, J.P., Sanglier, J. J., Vayssier, V., Veau, P., 1990. Moisissures utiles et nuisibles. Importance Industrielle. Masson, pp. 20-191.

Champion, R., 1997. Identifier les champignons transmis par les semences. In: Techniques et Pratiques. INRA Edn., 401p.

Cowan, M.M., 1999. Plant products as antimicrobial agents. Clin. Microbiol. Rev., 12: 564-582.

Djipa, C.D., Delmée M, Quetin-Leclercq, J., 2000. Antimicrobial activity of bark extracts of Syzygium jambos (L.) Alston (Myrtaceae). J. Ethnopharmacol., 12(71): 307-313.

Elfita, Mardiyanto, Fitrya, Larasati, J.E., Julinar, Widjajanti, H., Muharni, 2019. Antibacterial activity of Cordyline fruticosa leaf extracts and its endophytic fungi extracts. Biodiversitas, 20: 3804-3812.

Eze, P.M., Nnanna, J.C., Okezie, U., Buzugbe, H.S., Abba, C.C., Chukwunwejim, C.R., Okoye, F.B., Esimone, C.O., 2019. Screening of metabolites from endophytic fungi of some Nigerian medicinal plants for antimicrobial activities. EuroBiotech J., 3(1): 10-18.

Gouda, S., Das G., Sen, S. K., Shin, H-S., Patra, J. K., 2016. Endophytes: A treasure house of bioactive compounds of medicinal importance. Front. Microbiol., 7: 15-38.

Harbone, B., 1973. Phytochemical Methods. A Guide to Modern Techniques of Plant Analysis. London, Chapman and Hall Ltd., 116p. 
Harborne, J. B., Baxter H., Moss, G.P., 1999. Phytochemical Dictionary: A Handbook of Bioactive Compounds from Plants. $2^{\text {nd }}$ Edn., Taylor \& Francis, London.

Helander, M. L., 1994. Effects of heavy metals and acid irrigation on the birch rust, Melampsoridium betulinum. Eur. J. Forest Pathol., 24: 171-180.

Jalgaonwala, R.E., Mohite, B.V., Mahajan, R.T., 2011. A review: natural products from plant associated endophytic fungi. J. Microbiol. Biotechnol. Res., 1(2): 21-32.

Lacmata, T.S., Kuete, V., Dzoyem, J-P., Tankeo, S.B., Ngo, T.G., Kuiate, J.R., Pages, J-M., 2012. Antibacterial activities of selected Cameroonian plants and their synergistic effects with antibiotics against bacteria expressing MDR phenotypes. Evid. Based Complement. Alternat. Med., 623723, 11p.

Mativandlela, S.P.N., Lall, N., Meyer, J.J.M., 2006. Antibacterial, antifungal and antitubercular activity of Pelargonium reniforme (CURT) and Pelargonium sidoides (DC) (Geraniaceae) root extracts. S. Afr. J. Bot., 72: 232-237.

Muzzamal, H., Sarwar, R., Sajid, I., Hasnain, S., 2012. Isolation, identification and screening of endophytic bacteria antagonistic to biofilm formers. Pak. J. Zool., 44(1): 249-257.
Pitt, J. I., Hocking, A. D., 1985. Fungi and food spoilage. Academic Press Inc, Sydney. Orlando, San Diego, New York, London, Toronto, Montréal, Tokyo, p.414.

Rodrigues, C.G., Rafael, P., Ferreira, B., Sorandra, C., Mendes, O., Junior, R. R., Valerio, H.M., Brandi, I.V., de Oliveira, D A., 2014. Antibacterial activity of tannins from Psidium guineense Sw. (Myrtaceae). J. Med. Plants Res. 8(35): 1095-1100.

Scalbert, A., 1991. Antimicrobial properties of tanins. Phytochemistry, 30(12): 3875-3883.

Sharma, S., Roy, S., 2015. Isolation and identification of a novel endophyte from a plant Amaranthus spinosus. Int. J. Curr. Microbiol. Appl. Sci., 4(2): 785-798.

Strobel, G. A., 2003. Endophytes as sources of bioactive products. Microbes Infect., 5(6): 535-544.

Sushanto, G., Gitishree, D., Sen, S.K., 2016. Endophytes: A treasure house of bioactive compounds of medicinal importance. Front. Microbiol., 7(148): 1538.

Tamokou, J.D.D., Mbaveng, T.A., Kuete, V., 2017. Antimicrobial activities of African medicinal spices and vegetables. In: Medicinal Spices and Vegetables from Africa: Therapeutic Potential against Metabolic Inflammatory Infectious and Systemic Diseases, Academic Press, Cambridge, pp.207-237.

\section{How to cite this article:}

Lacmata, T. S., Tchoupe, T. G. B., Karimo, O., Kuiate, J. R., 2022. Antibacterial potential of some Cameroonian ornamental plants and their isolated endophytic fungi. Int. J. Curr. Res. Biosci. Plant Biol., 9(1): 19-31.

doi: https://doi.org/10.20546/ijcrbp.2022.901.003 